\title{
RABBIT VENTRICULAR MYOCYTE VOLUME CHANGES AS A DIRECT RESULT OF CRYSTALLOID CARDIOPLEGIA IN CONGESTIVE HEART FAILURE INDUCED BY AORTIC REGURGITATION
}

Jeffery S. Danetz, MD

Ruth D. Davies ${ }^{\mathrm{b}}$

Henry F. Clemo, MD, $\mathrm{PhD}^{\mathrm{b}, \mathrm{c}}$

Clive M. Baumgarten, $\mathrm{PhD}^{\mathrm{b}}$
Objectives: We hypothesized that the cell volume of ventricular myocytes isolated from hearts in volume-overload congestive failure would respond differently to hypothermic cardioplegia than would sham-operated cohorts.

Methods: Adult rabbits underwent either valvotomy and aortic regurgitation-induced heart failure or sham surgery. Congestive failure was confirmed clinically and by means of echocardiography. Cell volumes of isolated myocytes were measured by digital video microscopy. After equilibration in $37^{\circ} \mathrm{C}$ physiologic solution, cells were suprafused with $9^{\circ} \mathrm{C}$ standard or low- $\mathrm{Cl}^{-} \mathrm{St}$ Thomas' Hospital solution followed by reperfusion in $37^{\circ} \mathrm{C}$ physiologic solution.

Results: Exposure to cold St Thomas' Hospital solution for 20 minutes caused sham myocytes to swell by $8 \%(n=9)$; cell volumes fully recovered on normothermic reperfusion. In contrast, congestive failure myocytes $(\mathrm{n}=$ 9) maintained their cell volume in cold St Thomas' Hospital solution and during reperfusion. Lowering the $\left[\mathrm{K}^{+}\right]\left[\mathrm{Cl}^{-}\right]$product of St Thomas' Hospital solution by partially replacing $\mathrm{Cl}^{-}$with an impermeant anion prevented cellular edema in the sham group $(n=8)$ but caused a $4 \%$ swelling in failure myocytes $(n=10)$ on reperfusion. Osmotically shrinking the failure cells $(n=9)$ converted their behavior to that of sham cells.

Conclusions: In the absence of ischemia, congestive failure myocytes are less sensitive to cardioplegia-induced edema than sham cells. Low- $\mathrm{Cl}^{-}$cardioplegia, which prevents edema and protects the normal heart, induced swelling and may be detrimental in myopathic hearts. Differences in volume regulation in failure and sham myocytes may be due to activation of volumesensitive channels that are turned off by osmotic shrinkage. (J Thorac Cardiovasc Surg 2000;119:826-33)
$\mathrm{M}$ yocardial protection by means of cardioplegic arrest was first proposed by Melrose and colleagues ${ }^{1}$ almost half a century ago. Cardioplegic arrest offers enhanced tissue protection, has led to the exten-

From the Departments of Surgery, ${ }^{\mathrm{a}}$ Physiology, ${ }^{\mathrm{b}}$ and Internal Medicine (Division of Cardiology), ${ }^{\mathrm{c}}$ Medical College of Virginia, Virginia Commonwealth University, Richmond, Va.

Supported by National Institutes of Health grants HL-09817 (J.S.D. and C.M.B.) and HL-46764 (C.M.B.).

Received for publication June 28, 1999; revisions requested Sept 15, 1999; revisions received Oct 19, 1999; accepted for publication Nov 16, 1999.

Address for reprints: Clive M. Baumgarten, PhD, Department of Physiology, Box 980551, Medical College of Virginia, Virginia Commonwealth University, Richmond, VA 23298-0551 (E-mail: baumgart@hsc.vcu.edu).

Copyright (C) 2000 by The American Association for Thoracic Surgery.

0022-5223/2000 $\$ 12.00+0 \quad \mathbf{1 2 / 1 / 1 0 4 4 6 9}$

doi:10.1067/mtc.2000.104469 sion of surgical techniques, and provides the surgeon with a controlled environment in which to perform precision anastomoses. ${ }^{2}$ Despite these benefits, the sequelae of hyperkalemic arrest may be detrimental. Hyperkalemic arrest contributes to the development of myocardial edema, which has been implicated in left ventricular dysfunction, arrhythmogenesis, and a loss of compliance. ${ }^{3-5}$ Furthermore, myocardial edema contributes to the "no-reflow" phenomenon and diminishes drug efficacy. 6,7

It is well established that normal human and rabbit cardiomyocytes undergo cardioplegia-induced cell swelling in the absence of ischemia as a consequence of the composition of the cardioplegic solution. ${ }^{8-10}$ The cell volume of normal cardiomyocytes appears to be governed by a Donnan equilibrium under hypothermic conditions. As a result, exposure to cold isosmotic St Thomas' Hospital solution causes cell swelling because 
its $\left[\mathrm{K}^{+}\right]\left[\mathrm{Cl}^{-}\right]$product is higher than that of plasma. Moreover, methods directed at diminishing cellular edema by altering the $\left[\mathrm{K}^{+}\right]\left[\mathrm{Cl}^{-}\right]$product of St Thomas' Hospital solution correlate with an improved functional recovery after global ischemia in the intact heart. ${ }^{11}$ Although these studies are intriguing, they were conducted on normal myocytes. Consequently, the implications for diseased hearts is uncertain.

Patients with left ventricular dysfunction have an over 10-fold greater risk of perioperative mortality than subjects with normal ventricular function during coronary revascularization procedures. ${ }^{12}$ The failing heart exhibits an altered postischemic recovery of function ${ }^{13}$ and coronary vascular dysfunction ${ }^{13,14}$ when compared with the normal heart. In myocytes isolated from hearts with ventricular dysfunction, a decreased contractile function, decreased response to catecholamines, and altered calcium metabolism were noted during cardioplegic arrest and reperfusion. ${ }^{15}$

One possibility is that negative outcomes in dysfunctional hearts are caused in part by cellular edema. Recent studies suggest that myocyte cell volume regulation is altered in congestive heart failure $(\mathrm{CHF}) .^{16,17}$ In this setting ion channels with activities modulated by cell volume become persistently activated. Myocytes isolated from failure animals demonstrated several properties analogous to normal cells subjected to osmotic stress. We therefore hypothesized that cardioplegic solution tonicity, its effect on cell volume, is influenced by myocardial disease. We predicted that cellular edema caused by hypothermic cardioplegic solution would be different in myocytes isolated from a dilated CHF model ${ }^{18}$ than in sham-operated cohorts.

\section{Materials and methods}

Heart failure model. Heart failure was induced as previously described. ${ }^{18}$ Adult New Zealand White rabbits of either sex (2.5-3.0 kg, 3 months old) were randomized to one of two surgical intervention groups: (1) the CHF group underwent dilated cardiomyopathy induced by aortic regurgitation, and (2) the sham group underwent a sham operation. All animals received humane care in accordance with the Guide for the Care and Use of Laboratory Animals (revised 1996) prepared by the Institute of Laboratory Animal Resources and published by the National Academy Press. Rabbits were sedated (acepromazine maleate [INN: acepromazine], $2.5 \mathrm{mg} / \mathrm{kg}$; xylazine, $5 \mathrm{mg} / \mathrm{kg}$ ) and anesthetized (ketamine, $20 \mathrm{mg} / \mathrm{kg}$ ). Atropine $(0.25 \mathrm{mg} / \mathrm{kg})$ was given to avoid the bradycardic effect of xylazine.

In the CHF group aortic regurgitation was induced in a closed chest model. Aortic valvotomy was performed through the right internal carotid artery by using a $4 \mathrm{~F}$ dilator/sheath
(C.R. Bard, Inc, Billerica, Mass). Arterial pressures were continuously monitored through the inner lumen of the dilator. The dilator was advanced inside the sheath until resistance was encountered and a ventricular waveform was obtained. The dilator was then withdrawn back into the introducer, and the blood pressure was monitored for 5 minutes. Additional passes across the valve cusps were performed until the arterial pulse pressure widened by at least $10 \mathrm{~mm}$ $\mathrm{Hg}$. The right internal carotid artery was then ligated without event. In the sham group the right internal carotid artery was isolated and ligated. Ventricular function was assessed at 8 weeks with 2-dimensional echocardiography (HewlettPackard Sonos 2500, 7-MHz pediatric probe). By using the parasternal short-axis view, 2-dimensional images of the left ventricle were obtained at the mid papillary muscle level. At end-diastole and end-systole, left ventricular internal diameters (LVIDs) and left ventricular wall thicknesses were determined in both the anteroposterior and lateral directions. Fractional shortening of the left ventricle was calculated as follows: $\left(\mathrm{LVID}_{\text {diastole }}-\mathrm{LVID}_{\text {systole }}\right) / \mathrm{LVID}_{\text {diastole }}$.

Pulsed Doppler and color Doppler echocardiography were used to verify aortic regurgitation. At the time of death, all rabbits in the CHF group were noted to have pulmonary congestion and pleural and pericardial effusions. Grossly, hearts were markedly enlarged and hypertrophied.

Myocyte isolation. Isolated single ventricular cardiomyocytes were obtained from the two experimental groups by identical methods. Animals were sedated (acepromazine maleate, $25 \mathrm{mg} / \mathrm{kg}$; xylazine, $5 \mathrm{mg} / \mathrm{kg}$ ), heparinized (1000 $\mathrm{IU}$ ), and anesthetized (ketamine, $35 \mathrm{mg} / \mathrm{kg}$ ). Protocols for ventricular myocyte isolation with collagenase and pronase were previously described. ${ }^{8,10,19}$ Yields of rod-shaped, $\mathrm{Ca}^{2+}$ tolerant sham and CHF myocytes were similar.

Volume measurements. An aliquot of myocytes was placed in a glass-bottomed chamber and suprafused with $37^{\circ} \mathrm{C}$ physiologic Tyrode solution at a rate of 4.5 to $5.0 \mathrm{~mL} / \mathrm{min}$. Cells were allowed to equilibrate for at least 20 minutes before the application of experimental interventions. Cells selected for study remained adherent to the chamber bottom (coverslip) and were quiescent throughout the experiment.

Methods used for determining cell volume previously were described in detail. ${ }^{8-10,19}$ With each cell used as its own control, relative cell volume was calculated as follows:

$$
\begin{gathered}
\text { volume }_{\text {test }} / \text { volume }_{\text {control }}=\left(\operatorname{area}_{\text {test }} \times \text { width }_{\text {test }}\right) / \\
\left(\text { area }_{\text {control }} \times \text { width }_{\text {control }}\right) .
\end{gathered}
$$

Relative cell volume is independent of the assumed crosssectional shape of the myocyte. These methods provide estimates of relative cell volume that are reproducible to less than 1\%. ${ }^{8,10,19}$ Except as noted, all cell volume data are presented as the percentage change in relative cell volume by using each cell as its own control.

Experimental protocol. Protocols consisted of sequential equilibration, experimental, and reperfusion periods, each 20 minutes in duration. Cells were allowed to equilibrate and were reperfused in normothermic $\left(37^{\circ} \mathrm{C}\right)$ physiologic Tyrode solution. Experimental periods subjected the two groups of 
Table I. Echocardiographic parameters in the intact rabbit heart 8 weeks after surgery

\begin{tabular}{lcccr}
\hline Parameter & Sham & CHF & CHF-sham ratio & P value \\
\hline LVID $_{\text {diastole }}(\mathrm{cm})$ & $0.88 \pm 0.06$ & $1.49 \pm 0.09$ & 1.69 & $<.01$ \\
LVID $_{\text {systole }}(\mathrm{cm})$ & $0.52 \pm 0.03$ & $1.13 \pm 0.08$ & 2.17 & $<.01$ \\
LVWT $_{\text {diastole }}(\mathrm{cm})$ & $0.22 \pm 0.03$ & $0.26 \pm 0.05$ & 1.18 & .51 \\
LVIA $_{\text {diastole }}\left(\mathrm{cm}^{2}\right)$ & $0.62 \pm 0.04$ & $1.67 \pm 0.14$ & 2.69 & $<.01$ \\
LVIA $_{\text {systole }}\left(\mathrm{cm}^{2}\right)$ & $0.25 \pm 0.03$ & $0.92 \pm 0.08$ & 3.68 & $<.01$ \\
FS & $0.46 \pm 0.02$ & $0.27 \pm 0.03$ & 0.59 & $<.01$ \\
\hline
\end{tabular}

Mean \pm SEM for sham $(\mathrm{n}=4)$ and CHF $(\mathrm{n}=4)$ animals measured at end-systole and end-diastole by 2-dimensional echocardiography at 8 weeks. $L V I D$, Left ventricular internal diameter; $L V W T$, left ventricular wall thickness; $L V I A$, left ventricular internal cross-sectional area; $F S$, fractional shortening calculated as follows: $\left(\mathrm{LVID}_{\text {diastole }}-\mathrm{LVID}_{\text {systole }}\right) / \mathrm{LVID}_{\text {diastole }}$.

cells to either hypothermic $\left(9^{\circ} \mathrm{C}\right)$ cardioplegia with standard St Thomas' Hospital solution or low-Cl- $\mathrm{Cl}^{-}$Thomas' Hospital solution, which has demonstrated beneficial effects on cell volume in the normal myocyte. ${ }^{8-10}$ To determine whether the CHF group was behaving in a similar fashion to normal cells subjected to osmotic stress, CHF cells were artificially contracted in a hypertonic $(1.5 \mathrm{~T})$ normothermic Tyrode solution followed by suprafusion in a hypertonic $(1.5 \mathrm{~T})$ hypothermic $\left(9^{\circ} \mathrm{C}\right)$ St Thomas' Hospital solution and reperfusion in a hypertonic $(1.5 \mathrm{~T})$ normothermic Tyrode solution. Images for the repeated measurement of volume were acquired from each myocyte at 18 and 20 minutes of equilibration in physiologic Tyrode solution and then every 5 minutes during the experimental and reperfusion periods. Complete sets of volume measurements were obtained on $28 \mathrm{CHF}$ myocytes from 4 animals with aortic regurgitation and 17 control myocytes from 4 sham-operated animals.

Solutions. Modified Tyrode solution (osmolarity $=296 \pm 2$ mOsm; $\left[\mathrm{K}^{+}\right]\left[\mathrm{Cl}^{-}\right]$product $\left.=700 \mathrm{mmol}^{2} / \mathrm{L}^{2}\right)$ contained the following: $\mathrm{NaCl}, 130 \mathrm{mmol} / \mathrm{L} ; \mathrm{KCl}, 5 \mathrm{mmol} / \mathrm{L} ; \mathrm{MgSO}_{4}, 2$ $\mathrm{mmol} / \mathrm{L}$; glucose, $10 \mathrm{mmol} / \mathrm{L}$; and $N$-2-hydroxyethylpiperazine- $N$-2-ethanesulfonic acid, $5 \mathrm{mmol} / \mathrm{L}$; titrated to $\mathrm{pH} 7.4$ with $\mathrm{NaOH}$. Hyperosmotic Tyrode solution (osmolarity = $436 \pm 1 \mathrm{mOsm} ;\left[\mathrm{K}^{+}\right]\left[\mathrm{Cl}^{-}\right]$product $\left.=700 \mathrm{mmol}^{2} / \mathrm{L}^{2}\right)$ was made by adding $140 \mathrm{mmol} / \mathrm{L}$ mannitol to isosmotic Tyrode solution. St Thomas' Hospital solution (osmolarity = $292 \pm 1$ mOsm; $\left[\mathrm{K}^{+}\right]\left[\mathrm{Cl}^{-}\right]$product $\left.=2566.4 \mathrm{mmol}^{2} / \mathrm{L}^{2}\right)$ contained the following: $\mathrm{NaCl}, 110 \mathrm{mmol} / \mathrm{L} ; \mathrm{NaHCO}_{3}, 10 \mathrm{mmol} / \mathrm{L} ; \mathrm{MgCl}_{2}$, $16 \mathrm{mmol} / \mathrm{L} ; \mathrm{KCl}, 16 \mathrm{mmol} / \mathrm{L}$; and $\mathrm{CaCl}_{2}, 1.2 \mathrm{mmol} / \mathrm{L}$. To decrease the $\left[\mathrm{K}^{+}\right]\left[\mathrm{Cl}^{-}\right]$product of St Thomas' Hospital solution $\left(\mathrm{Cl}^{-}=160.4 \mathrm{mmol} / \mathrm{L}\right), \mathrm{Cl}^{-}$was partially substituted by equimolar concentrations of methanesulfonate, an impermeant anion. This low- $\mathrm{Cl}^{-}$variant of St Thomas' Hospital solution contained the following: Na-methanesulfonate, 110 $\mathrm{mmol} / \mathrm{L} ; \mathrm{NaHCO}_{3}, 10 \mathrm{mmol} / \mathrm{L} ; \mathrm{MgCl}_{2}, 16 \mathrm{mmol} / \mathrm{L} ; \mathrm{KCl}$, $9.35 \mathrm{mmol} / \mathrm{L}$; K-methanesulfonate, $6.65 \mathrm{mmol} / \mathrm{L}$; and $\mathrm{CaCl}_{2}$, $1.2 \mathrm{mmol} / \mathrm{L}$ (osmolarity $=293 \pm 2 \mathrm{mOsm} ;\left[\mathrm{K}^{+}\right]\left[\mathrm{Cl}^{-}\right]$product $\left.=700 \mathrm{mmol}^{2} / \mathrm{L}^{2} ;\left[\mathrm{Cl}^{-}\right]=43.75 \mathrm{mmol} / \mathrm{L}\right)$. Hyperosmotic $\mathrm{St}$ Thomas' Hospital solution (osmolarity $=440 \pm 3 \mathrm{mOsm}$; $\left[\mathrm{K}^{+}\right]\left[\mathrm{Cl}^{-}\right]$product $=2566.4 \mathrm{mmol}^{2} / \mathrm{L}^{2}$ ) was made by adding $140 \mathrm{mmol} / \mathrm{L}$ mannitol to St Thomas' Hospital solution. All variants of St Thomas' Hospital solution were bubbled with 95\% oxygen and 5\% carbon dioxide and adjusted to $\mathrm{pH}$ 7.4.
Statistical analysis. Results are expressed as means \pm SE, and $\mathrm{n}$ refers to the number of myocytes studied, except in Table I, where $\mathrm{n}$ refers to the number of hearts. All statistical calculations were performed by using SigmaStat 2.0 (SPSS, Inc, Chicago, Ill). A 1-way repeated-measures analysis of variance was used for sequential time-based measurements. Treatment significance was evaluated by an F ratio test, and individual treatment means were compared with control values by means of a Dunnett post test. The post test controls the overall error rate for all comparisons in the data set, and critical values were calculated at a $P$ value of less than .01 and a $P$ value of less than .05 . A $P$ value of less than .05 was accepted as statistically significant.

\section{Results}

Echocardiographic data. Table I summarizes echocardiographic data demonstrating that aortic regurgitation caused a substantial left ventricular dilation in the population studied at 8 weeks. Left ventricular internal diameter and left ventricular internal area were significantly increased $(P<.01)$ in both systole and diastole in CHF hearts compared with sham hearts. Fractional shortening in $\mathrm{CHF}$ hearts decreased by more than $40 \%(P<.01)$. No significant change in left ventricular wall thickness was detected, however $(P=.51)$. These data are consistent with those of Magid and colleagues, ${ }^{18}$ who found that an initial phase of hypertrophy in response to aortic regurgitation is supplanted by volume overload and dilation after 2 weeks and that dilatory changes reach a plateau after 6 weeks.

Myocyte volume. The initial volumes of sham and $\mathrm{CHF}$ myocytes after equilibration in $37^{\circ} \mathrm{C}$ physiologic Tyrode solution were estimated, assuming that myocytes are cylindrical. Aortic regurgitation induced about a $12 \%$ increase in cell volume from $57.9 \pm 4.1$ (n $=17)$ to $64.6 \pm 7.9 \mathrm{pL}(\mathrm{n}=19 ; P=.47$, unpaired $t$ test $)$. Because of the naturally occurring wide variation in myocyte size, these estimates may not precisely reflect population parameters. 


\section{A. SHAM}

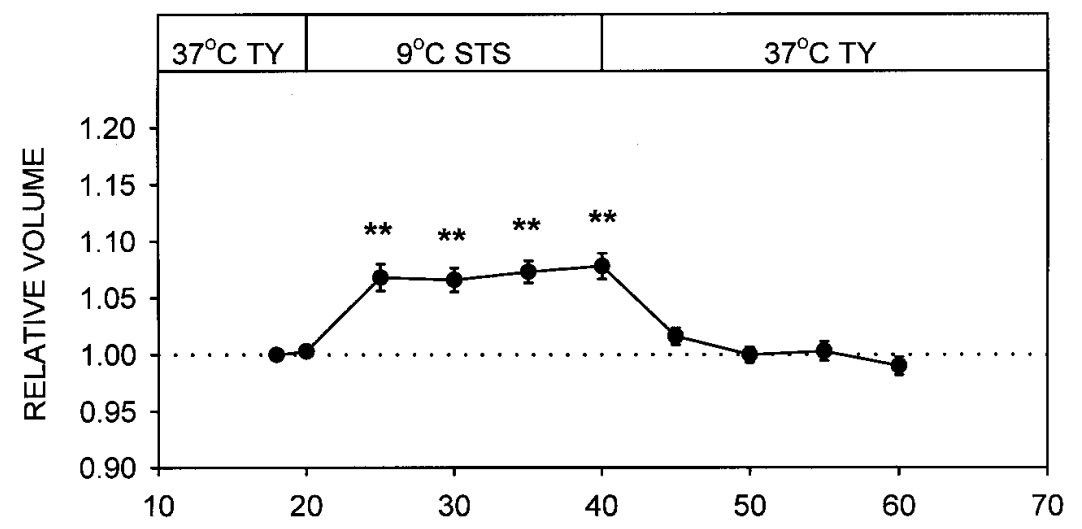

B. $\mathrm{CHF}$

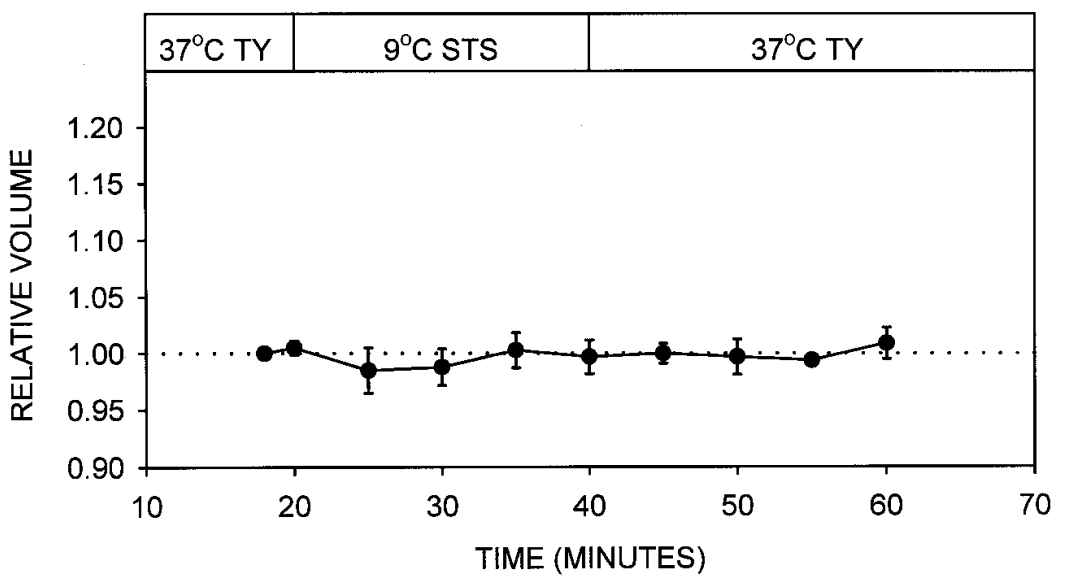

Fig 1. Effect of hypothermic cardioplegia and reperfusion in normothermic physiologic solution on relative cell volume in ventricular myocytes isolated from sham $(\mathbf{A}, n=9)$ and volume-overload CHF $(\mathbf{B}, n=9)$ hearts. After a 20-minute equilibration period in $37^{\circ} \mathrm{C}$ physiologic Tyrode solution (TY), myocytes were exposed to $9^{\circ} \mathrm{C} \mathrm{St}$ Thomas' Hospital solution (STS) for 20 minutes and then were reperfused with $37^{\circ} \mathrm{C}$ physiologic solution for 20 minutes. Each cell was used as its own control to calculate relative cell volume. A, Cold St Thomas' Hospital solution induced significant cellular edema in sham cells that fully reversed on reperfusion with normothermic physiologic solution. B, In contrast, the volume of CHF cells remained constant in cold St Thomas' Hospital solution and during normothermic reperfusion. ${ }^{*} P<.01$ compared with initial volume in physiologic solution.

The effect of St Thomas' Hospital solution on relative cell volume. The relative cell volume of sham myocytes was stable during 20 minutes in $37^{\circ} \mathrm{C}$ physiologic Tyrode solution. However, sham myocytes swelled during suprafusion of hypothermic $\left(9^{\circ} \mathrm{C}\right) \mathrm{St}$ Thomas' Hospital solution in the absence of ischemia (Fig 1, $A ; \mathrm{n}=9$ ). After 5 minutes, the relative cell volume of sham myocytes increased by $6.8 \% \pm 1.2 \%(P<$ $.01)$ and further increased to $7.8 \% \pm 1.2 \%(P<.01)$ after 20 minutes. On reperfusion in normothermic physiologic Tyrode solution, these cells returned to control volumes within 5 minutes, and cell volume remained constant throughout the remainder of the 20minute reperfusion period. In contrast, hypothermic St Thomas' Hospital solution did not significantly alter the volume of myocytes isolated from rabbits in CHF (Fig 1, B; $\mathrm{n}=9$ ) during either the 20-minute experimental period or the 20-minute normothermic physiologic reperfusion period $(P=.95)$. The swelling of sham myocytes in cold cardioplegic solution is similar to that previously observed in atrial and ventricular myocytes isolated from normal rabbit hearts ${ }^{8-10}$ and 


\section{A. SHAM}

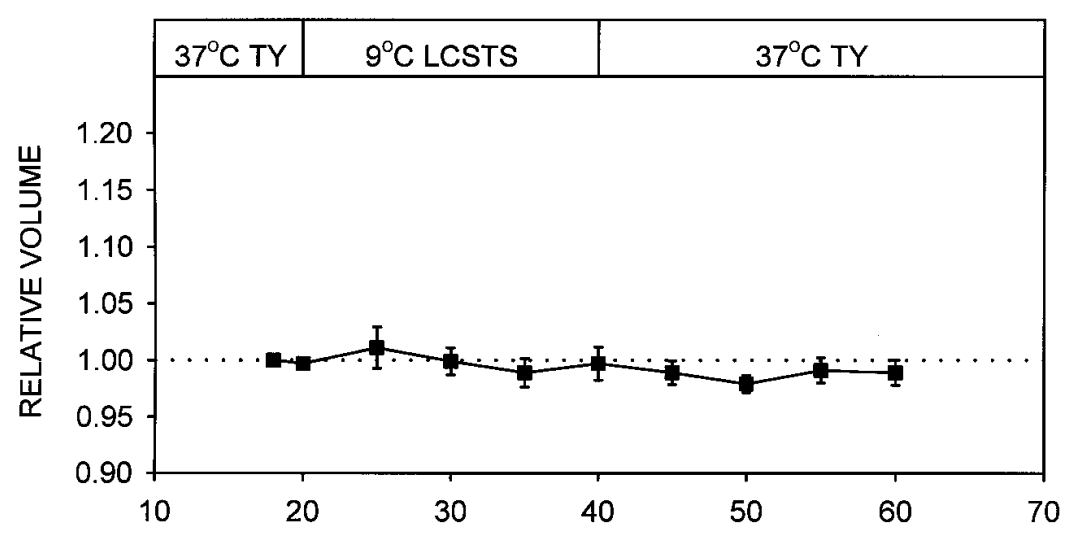

B. $\mathrm{CHF}$

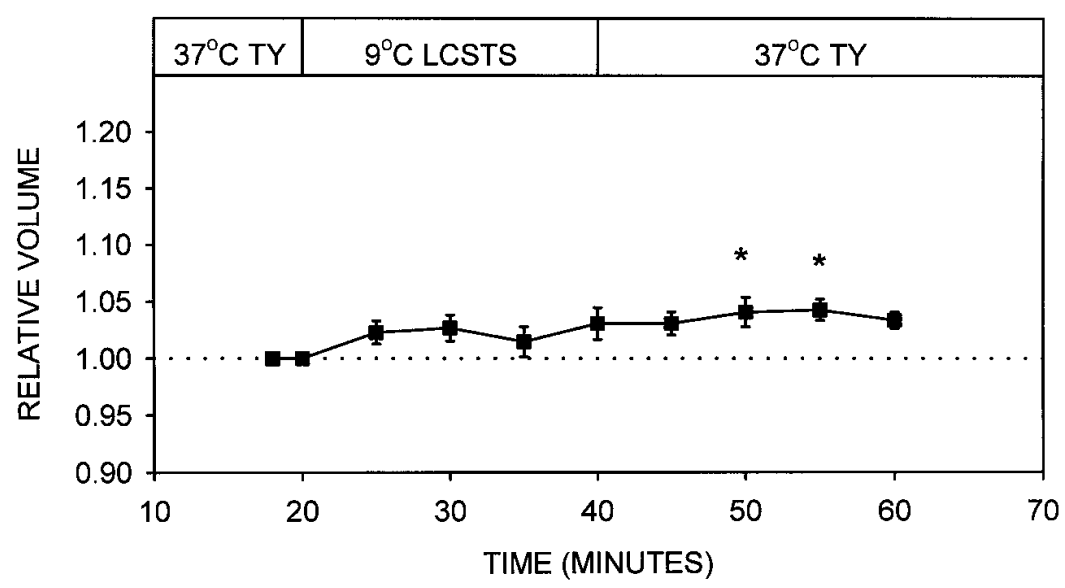

Fig 2. Effect of hypothermic low- $\mathrm{Cl}^{-}$St Thomas' Hospital solution on sham $(\mathbf{A}, \mathrm{n}=8)$ and $\mathrm{CHF}(\mathbf{B}, \mathrm{n}=10)$ myocytes. After a 20 -minute equilibration period in $37^{\circ} \mathrm{C}$ physiologic Tyrode solution (TY), myocytes were exposed to $9^{\circ} \mathrm{C}$ low- $\mathrm{Cl}^{-} \mathrm{St}$ Thomas' Hospital solution (LCSTS) for 20 minutes and then were reperfused with $37^{\circ} \mathrm{C}$ physiologic solution for 20 minutes. A, Low- $\mathrm{Cl}^{-}$St Thomas' Hospital solution prevented cellular edema during hypothermic cardioplegia in sham myocytes (compared with Fig 1, A). B, In contrast, exposure of CHF myocytes to low- $\mathrm{Cl}^{-}$St Thomas' Hospital solution caused a significant increase in cell volume during reperfusion. $* P<.05$ compared with initial volume in physiologic solution.

human atrial myocytes. ${ }^{9}$ This swelling was attributed to myocyte cell volume regulation according to a Donnan equilibrium in the cold. However, failure of CHF myocytes to swell suggests that volume regulation is more complicated in CHF cells.

The effect of low- $\mathrm{Cl}^{-} \mathrm{St}$ Thomas' Hospital solution on relative cell volume. We previously demonstrated that the detrimental edematous effects of St Thomas' Hospital solution can be ameliorated by reducing the $\mathrm{Cl}^{-}$concentration and thereby the $\left[\mathrm{K}^{+}\right]\left[\mathrm{Cl}^{-}\right]$product of St Thomas' Hospital solution $\left(2566.4 \mathrm{mmol}^{2} / \mathrm{L}^{2}\right)$ to a more physiologic range $\left(700 \mathrm{mmol}^{2} / \mathrm{L}^{2}\right)$ consistent with the internal milieu of the cell. ${ }^{8-10}$ Fig 2, A, demonstrates that volume regulation in the sham group of myocytes behaved as expected for cells governed by Donnan equilibrium. Sham myocytes $(n=8)$ maintained a constant volume during suprafusion in low- $\mathrm{Cl}^{-} \mathrm{St}$ Thomas' Hospital solution (compared with Fig 1,A) and remained at control volumes during normothermic physiologic reperfusion $(P=.48)$. Myocytes isolated from the CHF group (Fig 2, B; $\mathrm{n}=$ 10) also maintained constant volume during suprafusion of low- $\mathrm{Cl}^{-} \mathrm{St}$ Thomas' Hospital solution. In contrast to the sham group, CHF cells became edematous 


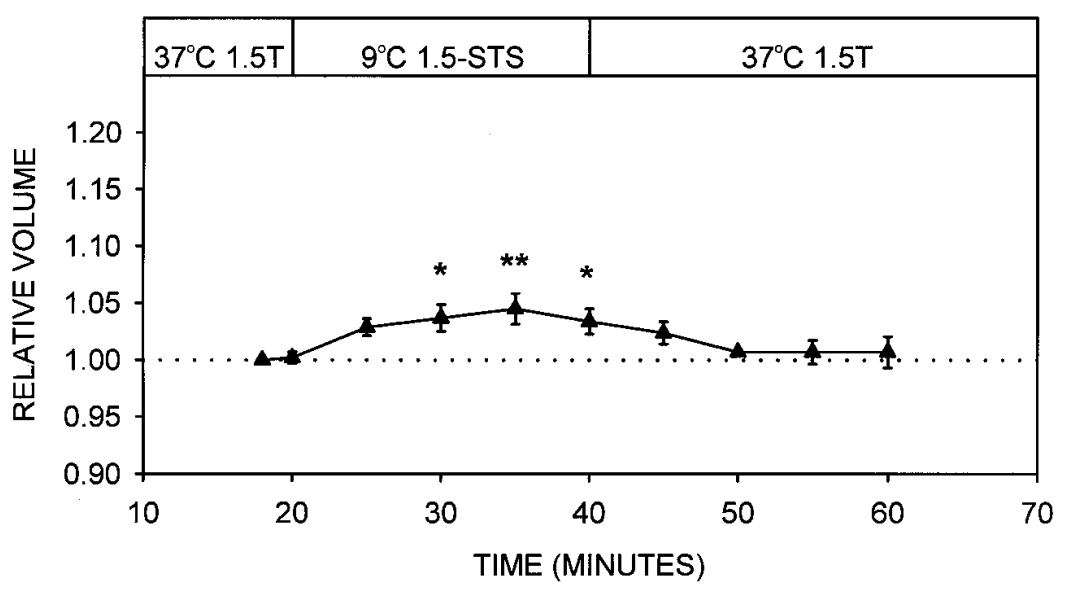

Fig 3. Effect of osmotic shrinkage on the response of CHF cells to cardioplegia. The osmolarity of both physiologic Tyrode solution and St Thomas' Hospital solution were increased to 1.5 times isosmotic by addition of mannitol. After a 20 -minute equilibration period in $37^{\circ} \mathrm{C}$ hyperosmotic Tyrode solution (1.5T), myocytes were exposed to $9^{\circ} \mathrm{C}$ hyperosmotic St Thomas' Hospital solution (1.5-STS) for 20 minutes and then were reperfused with $37^{\circ} \mathrm{C}$ hyperosmotic Tyrode solution for 20 minutes. CHF myocytes $(n=9)$ significantly swelled in cold hyperosmotic St Thomas' Hospital solution and fully recovered during reperfusion with normothermic hyperosmotic Tyrode solution. Osmotic shrinkage, which closes volume-sensitive ion channels, converted the behavior of CHF cells to that of sham cells (compared with Fig 1). Cell volumes were calculated relative to that in hyperosmotic Tyrode solution. ${ }^{*} P<.05 ; * * P<.01$ compared with initial volume in hyperosmotic Tyrode solution.

during reperfusion in normothermic physiologic solution. The swelling was statistically significant at 10 and 15 minutes $(4.1 \% \pm 1.3 \%[P<.05]$ and $4.3 \% \pm$ $1.0 \%[P<.05]$, respectively). Thereafter, these cells remained edematous, but the swelling did not reach statistical significance.

CHF cells under hypothermic hypertonic conditions behave similarly to sham cells in the cold. We previously demonstrated under isotonic conditions that myocytes isolated from hearts in CHF display chronic activation of $\mathrm{I}_{\mathrm{Cl}, \text { swell, }}{ }^{16}$ an outwardly rectifying $\mathrm{Cl}^{-}$current, and $\mathrm{I}_{\mathrm{Cir}, \mathrm{swell}}{ }_{17}$ an inwardly rectifying poorly selective cation current. These channels are only active in the normal myocyte when cells are subjected to osmotic swelling. By artificially shrinking CHF myocytes in hypertonic solutions, both volume-sensitive currents are turned off. ${ }^{16,17}$ If these volume-regulatory channels are playing an active role in the maintenance of cellular volume in failure myocytes, then one would expect that their inactivation should result in cellular swelling in cold cardioplegic solution similar to that noted in the normal heart.

Fig 3 shows the result of an experiment testing this idea. Previous studies ${ }^{16,17}$ showed that normal and CHF myocytes shrink by $20 \%$ to $25 \%$ in the hyperosmotic Tyrode solution used here. After an equilibration period in hyperosmotic Tyrode solution, CHF myocytes (n
= 9) were noted to swell in equally hyperosmotic hypothermic St Thomas' Hospital solution. Maximal swelling was noted at 15 minutes of suprafusion $(4.5 \%$ $\pm 1.4 \%, P<.01)$. These cells remained edematous throughout the remainder of the equilibration period and then returned to baseline volumes during normothermic hyperosmotic Tyrode solution reperfusion.

\section{Discussion}

Cellular edema during cardioplegia results from an inability of myocytes to appropriately maintain cell volume. Our understanding of cell volume regulation in the adult heart under hypothermic conditions is incomplete. During hypothermia, the volume of normal atrial and ventricular myocytes responds to the $\left[\mathrm{K}^{+}\right]\left[\mathrm{Cl}^{-}\right]$product of the bathing media as expected for a Donnan equilibrium. ${ }^{8-10}$ Under Donnan equilibrium, transmembrane ion fluxes keep the product of the $\mathrm{K}^{+}$ and $\mathrm{Cl}^{-}$concentrations on both sides of the plasmalemma equal. When normal myocytes are exposed to $\mathrm{St}$ Thomas' Hospital solution at $9^{\circ} \mathrm{C}$, a solution that is isosmotic but has a more than 3 -fold greater $\left[\mathrm{K}^{+}\right]\left[\mathrm{Cl}^{-}\right]$ product than plasma or crystalloid physiologic solutions, an influx of $\mathrm{K}^{+}$and $\mathrm{Cl}^{-}$is expected. Water passively follows this ion influx, and cellular edema occurs. ${ }^{8-10}$ Because ion channel and transporter function is temperature dependent, the extent of cell 
swelling during cardioplegia also can vary with temperature..$^{10}$ Even small changes in myocyte volume may have important implications for cardiac function in the intact heart when perfusion is restricted, as in cardioplegia. Shifts of water and ions from the small extracellular space to the much larger intracellular compartment will alter transmembrane ionic gradients, and cellular edema can limit reperfusion.

The present studies documented that ventricular myocytes from CHF hearts behave differently from normal myocytes in hypothermic St Thomas' Hospital solution. In contrast to previous results in normal cells, CHF cells maintained a constant volume during 20 minutes of $9^{\circ} \mathrm{C}$ hyperkalemic cardioplegia and normothermic reperfusion (Fig 1,B). Moreover, the volume of $\mathrm{CHF}$ cells was unaffected by low- $\mathrm{Cl}^{-} \mathrm{St}$ Thomas' Hospital solution, but surprisingly, cellular edema developed on normothermic physiologic reperfusion (Fig 2, B). These data imply that volume regulation in CHF cells during hypothermia and normothermic reperfusion cannot be fully explained by Donnan equilibrium. It is likely that the alterations in the intracellular ionic milieu that arise during cold cardioplegia in CHF myocytes are different from those in normal myocytes. Such differences may set the stage for the development of cellular edema on normothermic reperfusion of CHF cells.

The behavior of CHF cells was not due to operative manipulations because the results in sham-operated myocytes were consistent with previous studies of normal myocytes. ${ }^{8-10}$ As expected, sham myocytes rapidly swelled on exposure to hypothermic St Thomas' Hospital solution, and cell volume completely recovered on normothermic physiologic reperfusion (Fig 1, A). Exposing sham myocytes to a low- $\mathrm{Cl}^{-}$variant of $\mathrm{St}$ Thomas' Hospital solution with a physiologic $\left[\mathrm{K}^{+}\right]\left[\mathrm{Cl}^{-}\right]$ product $\left(700 \mathrm{mmol}^{2} / \mathrm{L}^{2}\right)$ completely prevented cardioplegia-induced cellular edema and confirmed that these cells follow Donnan equilibrium under hypothermic conditions (Fig 2, B).

Several pathologic changes occurring in the setting of heart failure relate to ion transport and thereby may directly or indirectly influence the development of cellular edema. Metabolically, there is a decrease in the nucleotide pool ${ }^{14}$ and altered calcium handling. ${ }^{15}$ The activity of the $\mathrm{Na}^{+}-\mathrm{Ca}^{2+}$ exchanger ${ }^{20}$ and $\mathrm{Na}^{+}-\mathrm{K}^{+}$ pump ${ }^{21}$ are diminished. In addition, we recently reported that cation ${ }^{17}$ and anion ${ }^{16}$ channels that are activated by osmotic swelling in normal cells were persistently turned on in CHF cells. These channels pass sufficient current to alter ionic gradients and can directly influence cell volume. Volume-sensitive channels are inhib- ited by osmotic shrinkage, ${ }^{16,17}$ and in the present study CHF cells in hyperosmotic cold St Thomas' Hospital solution (Fig 3) behaved much like sham cells under isosmotic conditions (Fig 1, A). Taken together, these data suggest that volume-sensitive channels may be important in minimizing the development of cellular edema in CHF cells during cardioplegia, although the contribution of other transport systems in limiting edema in CHF cells cannot be ruled out at the present time. Volume-sensitive channels also may be important for cell volume regulation during ischemia-induced edema.

Functional implications. Both intact myocardium and isolated cells from CHF hearts have a blunted response to inotropic agents and a decreased contractile function under basal conditions. ${ }^{13,15}$ Furthermore, cells isolated from failure hearts demonstrate a decreased contractile function after hyperkalemic arrest. ${ }^{14,22}$ These findings emphasize the need for a cardioplegic solution designed to optimize myocardial protection in $\mathrm{CHF}$ and diminish myocardial stunning. Jayawant and colleagues $^{11}$ demonstrated the beneficial effects of low- $\mathrm{Cl}^{-}$St Thomas' Hospital solution in ameliorating myocardial stunning and maintained atrioventricular conduction times in intact normal hearts, an improvement attributed to the prevention of cellular edema. It remains unclear whether low- $\mathrm{Cl}^{-}$St Thomas' Hospital solution also is beneficial in hypertrophic or dilated cardiomyopathy. If avoiding cell edema during cardioplegia is critical to the protection offered by low- $\mathrm{Cl}^{-} \mathrm{St}$ Thomas' Hospital solution in the normal heart, ${ }^{11}$ the present results suggest that this experimental cardioplegic solution would be detrimental in volume-overload failure. In a pressure-overload model of hypertrophy, Bénitah and colleagues ${ }^{23}$ described an outwardly rectifying $\mathrm{Cl}^{-}$channel that was persistently activated. It is unclear whether this anion channel is distinct from the one we previously described in volume-overload failure. ${ }^{16}$ Nevertheless, their finding raises the possibility that the cell volume response to cardioplegia in pressure overload-induced pathologic states also is distinct from that of normal myocardium.

Limitations of the study. These studies were performed on isolated myocytes, and extrapolation to the intact heart and the clinical situation requires caution. Although differences in cell volume regulation were identified in myocytes, it is unclear how the intact heart in volume-overload failure will respond to ischemic arrest in standard and low- $\mathrm{Cl}^{-} \mathrm{St}$ Thomas' Hospital solution. The role of autonomic, endocrine, and geometric factors that are present in the intact heart but not in iso- 
lated cells is unknown. Furthermore, confounding factors, such as cardiopulmonary bypass and ischemia, that are present in a clinical context were not included in the present study. Nevertheless, this study reinforces the idea that research performed in the normal heart should not be uncritically extrapolated to pathophysiologic states.

\section{Conclusion}

In the absence of ischemia, ventricular myocytes isolated from rabbits in $\mathrm{CHF}$ were more resistant to hypothermic cardioplegia-induced cellular edema than sham-operated cohorts. Altered cell volume regulation and the resistance to cellular edema may be due in part to the persistent activation of volume-sensitive channels in CHF cells and their contribution to cell volume regulation. Although low- $\mathrm{Cl}^{-} \mathrm{St}$ Thomas' Hospital solution offers improved myocardial protection in normal intact hearts, further work is necessary to evaluate whether this formulation is beneficial in the setting of poor ventricular function and CHF. Studies that consider ischemic and pressure-overload cardiomyopathies also would be useful.

\section{REFERENCES}

1. Melrose GG, Dryer G, Bentall HH, Baker JBE. Elective cardiac arrest. Lancet 1955;2:21.

2. Hearse DJ. Cardioplegia. Postgrad Med J 1983;59:11-24.

3. Foglia RP, Steed DL, Follette DM, DeLand E, Buckberg GD. Iatrogenic myocardial edema with potassium cardioplegia. J Thorac Cardiovasc Surg 1979;78:217-22.

4. Roberts AJ, Spies SM, Sangers JH, et al. Serial assessment of left ventricular performance following coronary artery bypass grafting: early postoperative results with myocardial protection afforded by multidose hypothermic potassium crystalloid cardioplegia. J Thorac Cardiovasc Surg 1981;81:69-84.

5. Cohen NM, Allen CA, Hsia PW, Nixon TE, Wise RM, Damiano RJ Jr. Electrophysiologic consequences of hyperkalemic cardioplegia during surgical ischemia. Ann Thorac Surg 1994;57:1076-83.

6. Powers ER, DiBona DR, Powell WJ Jr. Myocardial cell volume and coronary resistance during diminished coronary perfusion. Am J Physiol 1984;247:H467-77.

7. Wright AR, Rees SA. Cardiac cell volume: crystal clear or murky waters? A comparison with other cell types. Pharmacol Ther 1998;80:89-121.

8. Drewnowska K, Clemo HF, Baumgarten CM. Prevention of myocardial intracellular edema induced by St. Thomas' Hospital cardioplegic solution. J Mol Cell Cardiol 1991;23:1215-21.

9. Shaffer RF, Baumgarten CM, Damiano RJ Jr. Prevention of cellular edema directly caused by hypothermic cardioplegia: studies in isolated human and rabbit atrial myocytes. J Thorac Cardiovasc Surg 1998;115:1189-95.

10. Danetz JS, Clemo HF, Davies RD, Embrey RP, Damiano RJ Jr, Baumgarten CM. Age-related effects of St Thomas' Hospital cardioplegic solution on isolated cardiomyocyte cell volume. J Thorac Cardiovasc Surg 1999;118:467-76.

11. Jayawant AM, Stephenson ER, Baumgarten CM, Damiano RJ Jr. Prevention of cell swelling with low chloride St. Thomas' Hospital solution improves postischemic myocardial recovery. J Thorac Cardiovasc Surg 1998;115:1196-202.

12. Risum O, Nitter-Hauge S, Abdelnoor M, Levorstad K, Arafa O, Svennievig JL. Mortality and morbidity after coronary artery bypass surgery related to pre-operative left ventricular ejection fraction: a follow-up study. Eur Heart J 1996;17:874-9.

13. Tanguay M, Jasmin G, Blaise G, Dumont L. Resistance of the failing dystrophic hamster heart to the cardioprotective effects of diltiazem and clenitazem: evidence of coronary vascular dysfunctions. Can J Physiol Pharmacol 1995;73:1108-17.

14. Bouchard A, Watters TA, Wu S, et al. Effects of altered coronary perfusion pressure on function and metabolism of normal and cardiomyopathic hamster hearts. J Mol Cell Cardiol 1987;19:1011-23.

15. Dorman BH, Hebbar L, Clair MJ, Hinton RB, Roy RC, Spinale FG. Potassium channel opener-augmented cardioplegia: protection of myocyte contractility with chronic left ventricular dysfunction. Circulation 1997;96(Suppl):II-253-9.

16. Clemo HF, Stambler BS, Baumgarten CM. Swelling-activated chloride current is persistently activated in ventricular myocytes from dogs with tachycardia-induced congestive heart failure. Circ Res 1999;84:157-65.

17. Clemo HF, Stambler BS, Baumgarten CM. Persistent activation of a swelling-activated cation current in ventricular myocytes from dogs with tachycardia-induced congestive heart failure. Circ Res 1998;83:147-57.

18. Magid NM, Opio G, Wallerson DC, Young MS, Borer JS. Heart failure due to chronic experimental aortic regurgitation. Am J Physiol 1994;267:H556-62.

19. Clemo HF, Baumgarten CM. Atrial natriuretic factor decreases cell volume of rabbit atrial and ventricular myocytes. Am J Physiol 1991;260:C681-90.

20. McCall E, Ginsburg KS, Bassani RA, et al. Ca flux, contractility, and excitation-contraction coupling in hypertrophic rat ventricular myocytes. Am J Physiol 1998;274:H1348-60.

21. Ellingsen O, Holthe MR, Svindland A, Aksnes G, Sejersted OM, Ilebekk A. Na,K-pump concentration in hypertrophied human hearts. Eur Heart J 1994;15:1184-90.

22. Bristow MR, Ginsburg R, Umans V, et al. $\beta 1$ and $\beta 2$ adrenergicreceptor subpopulations in nonfailing and failing human ventricular myocardium: coupling of both receptor subtypes to muscle contraction and selective $\beta 1$-receptor down regulation. Circ Res 1986;59:297-309.

23. Bénitah J-P, Gomez M, Delgado C, Lorente P, Lederer J. A chloride current component induced by hypertrophy in rat ventricular myocytes. Am J Physiol 1997;272:H2500-6. 